VNU Journal of Science: Natural Sciences and Technology

Journal homepage: https://js.vnu.edu.vn/NST

Original Article

\title{
The Ability of Ginger Rhizome (Zingiber officinale Rosc) Extract in Producing of Silver Nanoparticles and the Antibacterial Activity of these Nanoparticles
}

\author{
Ho Thi Phuong, Nguyen Thi Le Na, Nguyen Trung Thanh, Nguyen Dinh Thang* \\ Faculty of Biology, VNU University of Science, 334 Nguyen Trai, Hanoi, Vietnam
}

Received 02 July 2019

Revised 24 July 2019; Accepted 25 July 2019

\begin{abstract}
Recently, using plant extract as a reducing agent for nanosilver particle synthesis has been focused. This is a green technology utilizing the ready material in the nature to create the nanoparticles with good properties and uniqe quality. In this study, ginger rhizome extract was used to reduce the silver cation $\left(\mathrm{Ag}^{+}\right)$to silver $\left(\mathrm{Ag}^{\mathrm{o}}\right)$ as nanoparticles with uniqe quality and even distribution in the solution. The size of the particles varied in the range of $20-40 \mathrm{~nm}$. Reaction conditions were investigated and optimized with $\mathrm{AgNO}_{3}$ concentration of $3 \mathrm{mM}$, extract solution $/ \mathrm{AgNO}_{3}$ solution of $1 / 5$, temperature of $80{ }^{\circ} \mathrm{C}$, $\mathrm{pH}$ of 12 and reaction time of $30 \mathrm{~min}$. The results obtained from the antibacterial assays showed that silver nanoparticle solution had antibacterial ability with an average effective diameter of $10 \mathrm{~mm}$. It also indicated that the antibacterial activity of silver nanoparticle solution on the Gram (-) bacterium (E. coli) is better that on Gram (+) bacterium ( $S$. aureus). In conclusion, we suggest that the ginger rhizome extract can be used to produce silver nanoparticles in mild reaction conditions; the silver nanoparticle solution expressed as a quite good antibacterial agent and therefore could be applied in decreasing the effects of deleterious bacteria.
\end{abstract}

Keywords: Silver nanoparticle, plant extract, antibacterial, Zingiber officinale Rosc.

\footnotetext{
* Corresponding author.

Email address: ndthang@ hus.edu.vn

https://doi.org/10.25073/2588-1140/vnunst.4922
} 


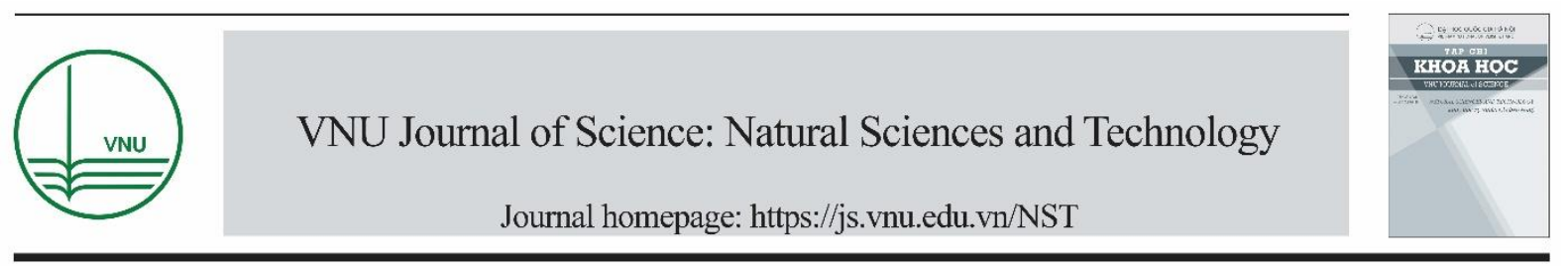

Nghiên cứu khả năng ứng dụng dịch chiết củ Gừng (Zingiber officinale Rosc) để chế tạo hạt nano bạc và đánh giá khả năng
kháng khuẩn

\author{
Hồ Thị Phương, Nguyễn Thị Lê Na, Nguyễn Trung Thành, Nguyễn Đình Thắng*
}

Khoa Sinh học, Truờng Đại học Khoa học Tự nhiên, ĐHQGHN, 334 Nguyễn Trãi, Hà Nội, Việt Nam

Nhận ngày 02 tháng 7 năm 2019

Chỉnh sửa ngày 24 tháng 7 năm 2019; Chấp nhận đăng ngày 25 tháng 7 năm 2019

\begin{abstract}
Tóm tắt: Tổng hợp nano bạc bằng phương pháp sử dụng các dịch chiết thực vật đang được nhiều nhóm nghiên cứu trên thế giới chú trọng vì những ưu điểm như chất lượng đồng nhất, tận dụng được nguồn nguyên liệu sẵn có và thân thiện môi trường. Trong nghiên cứu này chúng tôi sử dụng dịch chiết củ gừng để tổng hợp nano bạc từ ion bạc. Các điều kiện phản ứng tổng hợp đã được khảo sát và tối ưu với kết quả như sau: nồng độ $\mathrm{AgNO}_{3}: 3 \mathrm{mM}$; tỷ lệ dịch chiết/dung dịch $\mathrm{AgNO}_{3}$ : 1/5; nhiệt độ: $80{ }^{\circ} \mathrm{C}$; pH: 12; thời gian phản ứng: 30 phút. Ở điều kiện tối ưu này, các hạt nano bạc được tạo ra có kích thước đồng đều trong khoảng từ $20-40 \mathrm{~nm}$. Kết quả nghiên cứu khả năng kháng khuẩn cũng cho thấy dung dịch nano bạc có khả năng kháng khuẩn ở mức độ trung bình với vòng kháng khuẩn khoảng $10 \mathrm{~mm}$ và tính kháng khuẩn thể hiện tốt hơn trên vi khuẩn gram (-) $E$. coli so với vi khuẩn Gram (+) S. aureus. Từ các kết quả thu được, chúng tôi kết luận rằng sử dụng dịch chiết củ Gừng để tạo dung dịch nano bạc có thể thực hiện được một cách dễ dàng, hiệu quả tốt trong các điều kiện không khắt khe. Dung dịch nano bạc có thể ứng dụng trong việc kháng lại các vi sinh vật gây bệnh trong môi trường.
\end{abstract}

Từ khóa: Nano bạc, dịch chiết thực vật, kháng khuẩn, củ Gừng.

\section{1. Đặt vấn đề}

Công nghệ nano liên quan đến việc thiết kế, phân tích, chế tạo và ứng dụng các cấu trúc, thiết bị và hệ thống bằng việc điều khiển hình dáng, kích thước trên quy mô nanomet (nm). Ở kích thước nano, vật liệu thường thể hiện tính chất đặc biệt cũng như sự thay đổi đáng kể về những đặc

\footnotetext{
* Tác giả liên hệ.

Địa chi email: ndthang@hus.edu.vn

https://doi.org/10.25073/2588-1140/vnunst.4922
}

điểm vật lý, hóa học và sinh học so với vật liệu truyền thống do sự thu nhỏ kích thước và việc tăng diện tích bề mặt [1]. Do có nhiều tính năng độc đáo và kích thước tương đương với các phân tử sinh học nên hiện nay, công nghệ nano đang được đầu tư nghiên cứu và được ứng dụng trong nhiều lĩnh vực, đặc biệt là lĩnh vực y sinh [2-4]. 
Hạt nano bạc đã được nghiên cứu trong nhiều thập kỷ qua bởi những đặc tính độc đáo cũng như ứng dụng đa dạng của nó. Hạt nano bạc được sử dụng gần như khắp mọi nơi: mỹ phẩm, hộp đựng đồ ăn, chất tẩy rửa, thuốc xịt côn trùng và trong những sản phẩm khác để ngăn ngừa sự lây lan của các mầm bệnh $[5,6]$. Hạt nano bạc xâm nhập bên trong tế bào và làm mất ổn định cấu trúc nội bào và phân tử sinh học. Sau khi dính vào màng tế bào, nano bạc cũng có thể xâm nhập vào bên trong tế bào chất, tương tác với cấu trúc tế bào và các phân tử sinh học như protein và DNA [711]. Sự tương tác này có thể gây ra sự đứt gãy hoặc biến tính DNA và làm gián đoạn sự phân chia tế bào $[12,13]$.

Có nhiều phương pháp chế tạo hạt nano bạc, chẳng hạn như: phương pháp ăn mòn laze, phương pháp khử hóa học, phương pháp khử vật lý, phương pháp khử hóa lý và phương pháp khử sinh học [2 - 4]. Trong các phương pháp này, phương pháp sinh tổng hợp có các ưu điểm lớn là rất đơn giản, chi phí thấp mà đạt hiệu quả, đồng thời còn cho năng suất cao và thân thiện với môi trường $[14,15]$. Theo một vài nghiên cứu, nhóm - $\mathrm{OH},-\mathrm{CO}$ có trong các nhóm chất như flanovoid, saponin, tanin...trong dịch chiết thực vật đóng vai trò như tác nhân khử [15]. Chính vì vậy, nhóm thực vật được lựa chọn sử dụng để tổng hợp nano bạc có chứa nhiều flavonoid, tannin và saponin. Những chất này đóng vai trò như tác nhân khử khử các ion bạc để sản xuất hạt nano bạc với hoạt tính kháng khuẩn.

Gừng (Zingiber officinale Rosc) là một vị thuốc quý, được sử dụng nhiều trong dân gian. Trong củ gừng có chứa nhiều các hợp chất có hoạt tính sinh học như alkaloids, flanovoids, zingiberene, gingerols và shogaols có tính khử mạnh [16 - 18]. Vì vậy, trong nghiên cứu này, chúng tôi tiến hành tối ưu các điều kiện sinh tổng hợp hạt nano bạc sử dụng dịch chiết củ gừng, đồng thời đánh giá hiệu quả kháng khuẩn của hạt nano bạc tạo thành lên hai chủng vi khuẩn gây bệnh là Staphylococcus aureus và Escherichia coli.

\section{Vật liệu và phương pháp nghiên cứu}

\subsection{Nguyên vật liệu}

Củ Gừng được mua từ siêu thị và được định danh tại Khoa Sinh học, Trường Đại học Khoa học Tự nhiên, ĐHQGHN. Các chủng chuẩn vi sinh vật dùng thử nghiêm bao gồm $S$. aureus và E. coli được cung cấp từ Phòng thí nghiệm Trọng điểm Công nghệ Enzyme và Protein, Trường Đại học Khoa học Tự nhiên, ĐHQGHN.

\subsection{Phuơng pháp chuẩn bị mẫu}

Củ Gừng tươi sau khi loại bỏ lớp vỏ bên ngoài, rửa sạch để loại bỏ bùn đất và để ráo nước. Tiếp đó, củ gừng được cắt thành từng mảnh nhỏ $(<5 \mathrm{~mm})$ và được sấy khô ở $50{ }^{\circ} \mathrm{C}$, sau đó được gói kỹ trong giấy bạc và bảo quản ở $4{ }^{\circ} \mathrm{C}$ cho đến khi cần phân tích. Mẫu củ gừng được chiết trong nước cất ấm $40{ }^{\circ} \mathrm{C},(\mathrm{pH}$ trong khoảng từ 7 đến 8$)$ để thu dịch chiết.

\subsection{Phân tích bằng phổ UV-VIS}

UV-VIS (Ultraviolet-visible spectroscopy) là phương pháp phân tích sử dụng phổ hấp thụ hoặc phản xạ trong vùng cực tím cho tới vùng ánh sáng nhìn thấy được. Các hạt nano bạc có hình cầu chỉ có một bề mặt plasmon duy nhất nên trong phổ UV-VIS của chúng chỉ xuất hiện 1 đỉnh duy nhất, và được ghi nhận là tại bước sóng $415 \mathrm{~nm}$.

\subsection{Phân tích bằng kính hiển vi điện tư quét}

Kính hiển vi điện tử quét (SEM) là một loại kính hiển vi điện tử có thể tạo ra ảnh với độ phân giải cao của bề mặt mẫu vật bằng cách sử dụng một chùm điện tử (chùm các electron) hẹp quét trên bề mặt mẫu. Việc tạo ảnh của mẫu vật được thực hiện thông qua việc ghi nhận và phân tích các bức xạ phát ra từ tương tác của chùm điện tử với bề mặt mẫu vật. Hạt nano bạc được chụp dưới $\mathrm{SEM}$ và được phân tích kích cỡ hạt và phân bố hạt. 


\subsection{Tối ưu các thông số hóa lý ảnh hưởng đến quá trình tạo nano bạc}

Các thông số hóa lí gồm: tỷ lệ chiết rắn lỏng, nồng độ $\mathrm{AgNO}_{3}$, tỷ lệ dịch chiết/dung dịch $\mathrm{AgNO}_{3}$, nhiệt độ tối ưu, $\mathrm{pH}$ tối ưu và thời gian tối ưu được khảo sát và đánh giá.

\subsection{Xác định khả năng kháng khuẩn của mẫu nano bạc tạo tù̀ dịch chiết củ gù̀ng}

Hoạt tính kháng khuẩn của dung dịch nano bạc tạo thành được xác định theo phương pháp khuếch tán trên thạch. Chủng vi sinh vật được chọn bao gồm: vi khuẩn gram (-): E. coli và vi khuẩn gram (+): S. aureus. Nguyên tắc: vi sinh vật thử nghiệm được cấy trải trên môi trường dinh dưỡng, sau đó tạo những lỗ thạch và nhỏ dung dịch cần thử hoạt tính vào các lỗ. Để đĩa đã nhỏ dung dịch vào tủ lạnh ở $4{ }^{\circ} \mathrm{C}$ một khoảng thời gian phù hợp để dung dịch khuếch tán hết vào thạch đồng thời ức chế sự sinh trưởng của vi khuẩn. Sau khi dung dịch đã khuếch tán hết vào thạch, đĩa được ủ ở nhiệt độ thích hợp trong khoảng $18-24 \mathrm{~h}$ và quan sát sự xuất hiện của vòng kháng khuẩn. Nếu xung quanh lỗ thạch có vòng kháng khuẩn chứng tỏ dung dịch cần thử nghiệm có hoạt tính kháng khuẩn. Dung dịch nano bạc cần thử hoạt tính được chuẩn bị ở các nồng độ khác nhau: gốc, pha loãng 2 lần, pha loãng 3 lần, pha loãng 4 lần, pha loãng 5 lần, pha loãng 10 lần và đánh số từ 1 đến 6 theo thứ tự. Đường kính vòng kháng khuẩn được đo bằng đơn vị mm theo công thức: $\mathrm{D}=\mathrm{D}_{1}-\mathrm{D}_{2}$. Trong đó: $\mathrm{D}$ là đường kính vòng kháng khuẩn, $\mathrm{D}_{1}$ là đường kính vòng kháng và đường kính lỗ thạch và $\mathrm{D}_{2}$ là đường kính lỗ thạch. Tính kháng khuẩn được biểu hiện: đường kính vòng kháng khuẩn $<5 \mathrm{~mm}$ : tính kháng yếu, đường kính vòng kháng khuẩn từ 5 đến $10 \mathrm{~mm}$ : tính kháng trung bình và đường kính vòng kháng khuẩn $>10 \mathrm{~mm}$ : tính kháng mạnh.

\section{Kết quả và thảo luận}

\subsection{Khảo sát khả năng tạo phân tủ nano bạc}

Sự hình thành phân tử nano bạc được đánh giá bằng việc thay đổi màu của dung dịch từ không màu (Hình $1 \mathrm{~A}$ ) sang màu vàng nâu (Hình 1B) khi thêm dung dịch muối bạc nồng độ $2 \mathrm{mM}$ vào 3 dịch chiết củ gừng $2,5 \mathrm{~g} / 100 \mathrm{~mL}(\mathrm{M} 1), 5$ $\mathrm{g} / 100 \mathrm{~mL}(\mathrm{M} 2)$ và $7,5 \mathrm{~g} / 100 \mathrm{~mL}(\mathrm{M} 3)$ và để phản ứng xảy ra trong 30 phút, tại nhiệt độ $80^{\circ} \mathrm{C}$. Tiến hành đo độ hấp thụ quang trong một dãy bước sóng từ $300 \mathrm{~nm}-600 \mathrm{~nm}$ cho thấy cực đại hấp thụ của dung dịch nano bạc là $\lambda=412 \mathrm{~nm}$. Khi tăng dần khối lượng củ gừng thì màu vàng cũng đậm dần, tuy nhiên nếu tăng khối lượng gừng quá cao thì quá trình hình thành nano bạc quá nhiều và có hiện tượng keo tụ và tạo thành các hạt có kích thước có khả nắng tụ và dẫn tới sự giảm giá trị mật độ quang (Hình $1 \mathrm{C}$ ). Hạt nano bạc hình thành được chụp bằng SEM và hình ảnh từ SEM xác nhận sự tạo thành của hạt nano bạc có hình cầu với kích thước khá đồng nhất và dao động trong khoảng 20 - 40 nm (Hình 1D).

\subsection{Anh hưởng nồng độ ion bạc đến khả năng hình thành nano bac}

Ion bạc $\left(\mathrm{AgNO}_{3}\right)$ trong dãy nồng độ từ 0,5 $\mathrm{mM}$ (M1), 1,0 mM (M2), 1,5 mM (M3), 2,0 mM (M4), 3,0 mM (M5) và 4,0 mM (M6) được sử dụng để thêm vào dịch chiết củ gừng $(5 \mathrm{~g} / 100$ $\mathrm{mL})$. Phản ứng xảy ra trong 30 phút, tại nhiệt độ $80^{\circ} \mathrm{C}$. Quan sát màu sắc của các ống nghiệm (1-6) trên Hình 2A-B cho thấy, màu của dung dịch thay đổi từ không màu sang màu vàng nhạt, chứng tỏ sự tạo thành của phân tử nano bạc. Khi nồng độ $\mathrm{AgNO}_{3}$ tăng dần từ $0,5 \mathrm{mM}$ đến $4 \mathrm{mM}$, dung dịch chuyển từ màu vàng nhạt sang màu vàng đậm và đạt cực đại tại nồng độ $3 \mathrm{mM}$ với giá trị độ hấp thu quang $=0,422$, tại bước sóng $\lambda$ $=412 \mathrm{~nm}$ (Hình 2C). Tại nồng độ $4 \mathrm{mM}$, giá trị mật độ quang giảm có thể giải thích là do hạt nano bạc tạo ra ở nồng độ này có kích thước lớn, gây ra keo tụ các hạt nano bạc. 


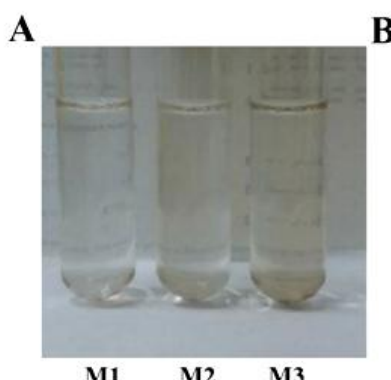

C

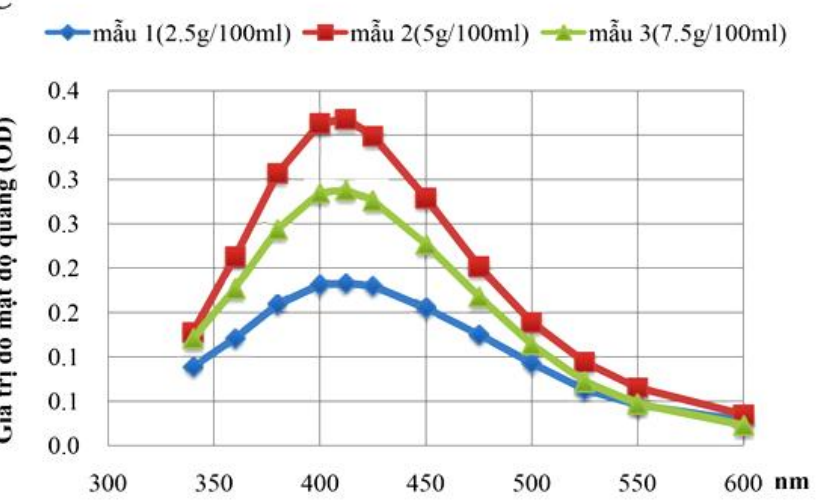

B

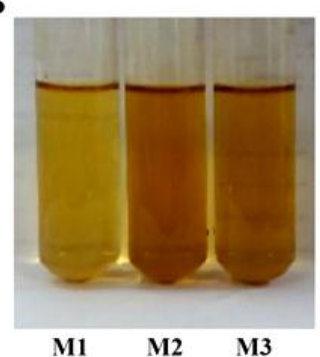

D

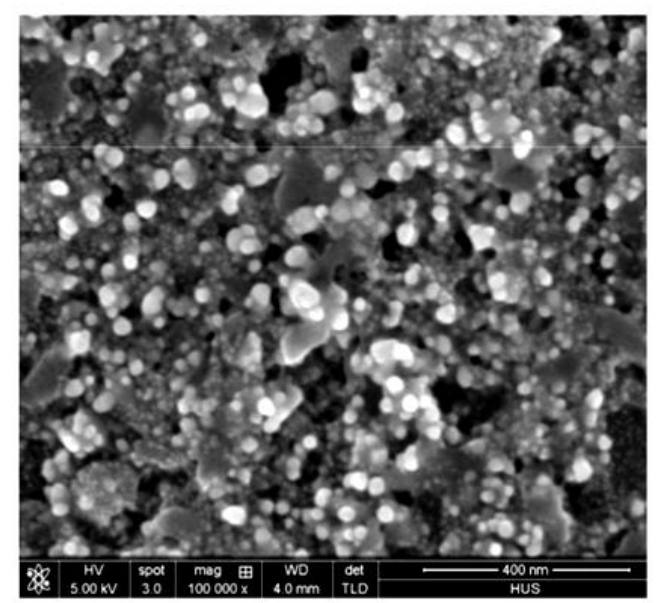

Hình 1. Sự chuyển màu của dung dịch không màu sang màu vàng nâu khi hình thành nano bạc (A và $\mathrm{B})$. Độ hấp thụ quang của dung dịch nano bạc trong dãy bước sóng khảo sát từ 300 - 600 nm (C), và Hình ảnh hạt nano bạc chụp bằng SEM (D).

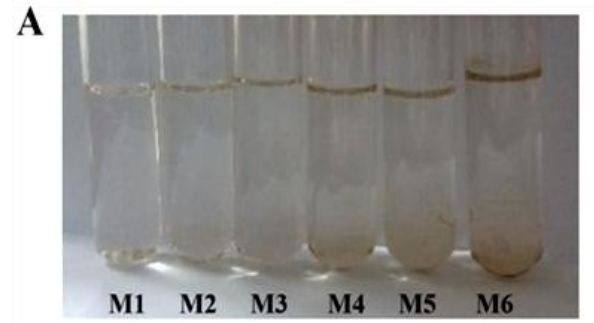

B

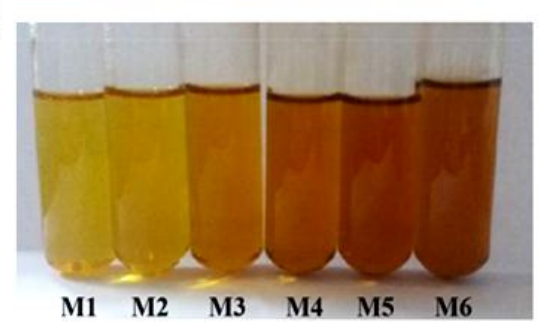

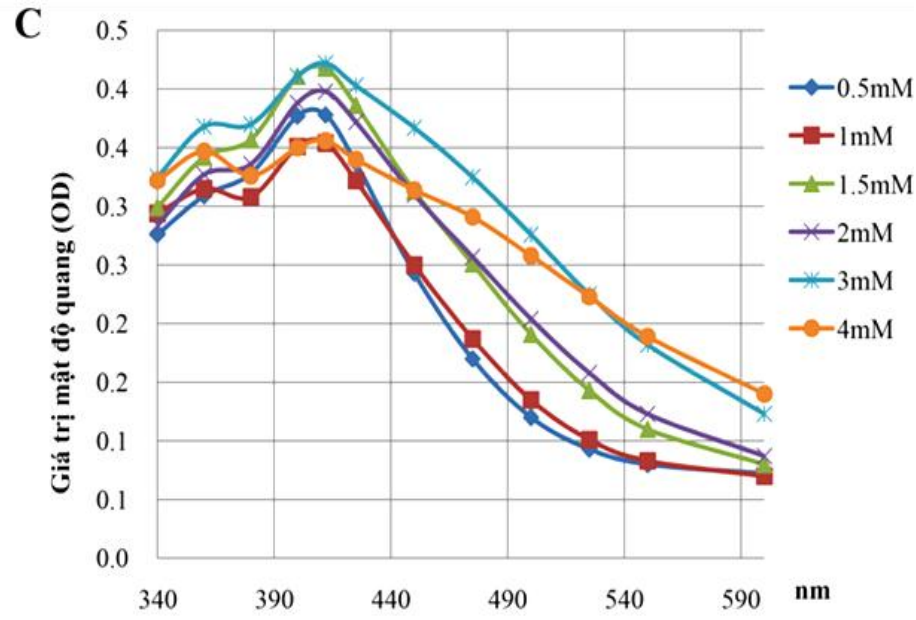

Hình 2. Dung dịch nano bạc được tạo từ dịch chiết củ gừng ở nhừng nồng độ $\mathrm{AgNO}$ khác nhau từ $0,5-4,0 \mathrm{mM}$ (A-B), với mật độ quang cực đại tại 412 nm (C). 


\subsection{Anh hưởng của tỉ lệ dịch chiết/dung dịch ion bạc lên khả năng tạo nano bạc}

Phản ứng xảy ra trong 30 phút, tại nhiệt độ $80^{\circ} \mathrm{C}$. Khi tăng thể tích dịch chiết trong khi giữ nguyên thể tích dung dịch ion bạc để tạo ra các tỉ lệ dịch chiết $(5 \mathrm{~g} / 100 \mathrm{~mL}) /$ dung dịch $\mathrm{AgNO} 3$ (3 mM) khác nhau từ $1 / 15,1 / 12,1 / 10,1 / 9,1 / 8$ và
1/5 thì dung dịch nano bạc thu được cũng có màu từ vàng dậm dần từ tỉ lệ $1: 15$ đến $1: 5$ (hình $3 \mathrm{~A}$ B). Khi đo mật độ hấp thu quang cũng cho thấy giá trị mật độ quang tăng dần từ tỉ lệ $1: 15$ đến $1 / 5$ (Hình $3 \mathrm{C}$ ). Điều này có thể lý giải do khi tăng thể tích dịch chiết, lượng chất khử có mặt nhiều và làm tăng hiệu quả khử ion $\mathrm{Ag}^{+}$thành $\mathrm{Ag}^{0}$.
A

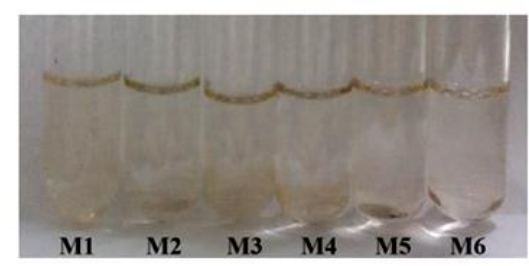

B

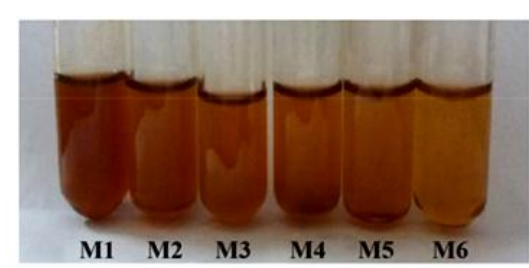

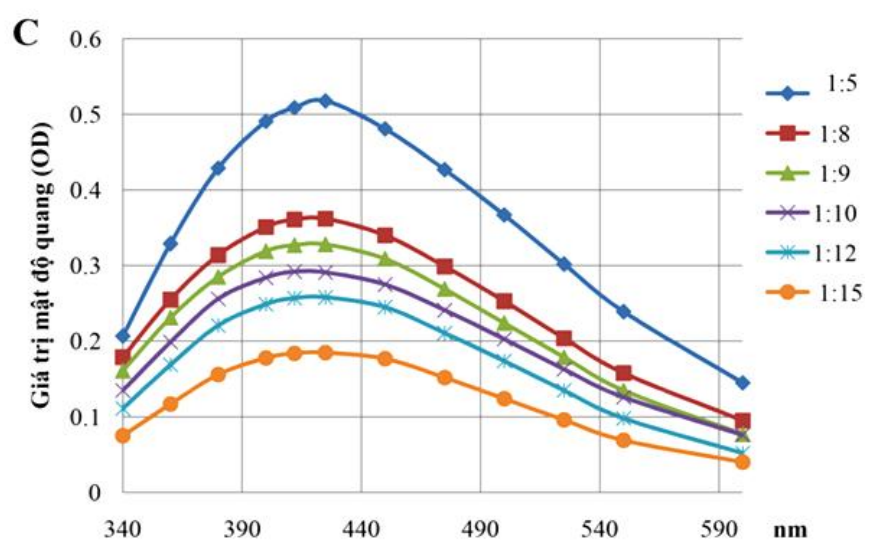

Hình 3. Sự tạo thành nano bạc trong dịch chiết củ Gừng ở các thể tích khác nhau.

\subsection{Anh hưởng của điều kiện $p H$ lên khả năng tao nano bac}

Ảnh hưởng chính của $\mathrm{pH}$ đến khả năng tạo nano bạc là do khả năng làm thay đổi điện tích của các hợp chất sinh học, ảnh hưởng đến sự ổn định và sự phát triển của hạt nano bạc [19]. Phản ứng xảy ra trong 30 phút, tại nhiệt độ $80^{\circ} \mathrm{C}$. Khi thay đồi pH trong dãy từ 3-13, kết quả đo mật độ quang (OD) cho thấy ở $\mathrm{pH} 8$ (gần với $\mathrm{pH}$ của dịch chiết trong nước) giá trị OD của dung dịch nano bạc cũng khá tốt, tuy nhiên OD cực đại ở pH 10 (Hình 4). Đây là pH tối ưu cho sự hình thành nano bạc (Hình 4). Trong khi đó ở những pH thấp (3 - 5) hay pH quá cao (13), giá trị OD là rất thấp, chứng tỏ khả năng tạo thành hạt nano kém.

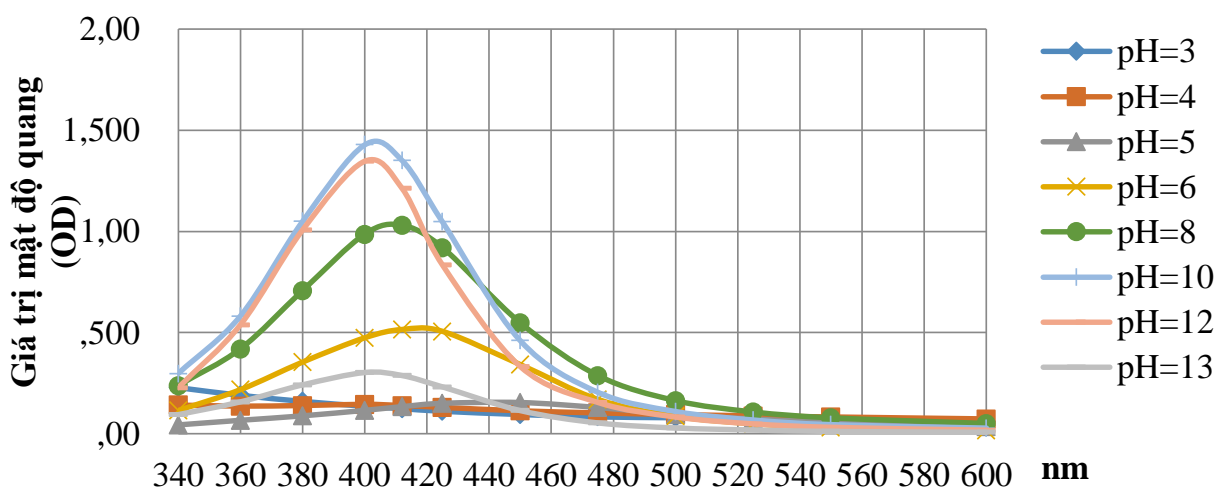

Hình 4. Dung dịch nano bạc được tạo từ dịch chiết củ gừng ở những điều kiện pH khác nhau, thay đổi trong dãy từ từ 3-13. 


\subsection{Anh hưởng của nhiệt độ lên khả năng tạo nano bac}

Khảo sát sự ảnh hưởng của nhiệt độ đến sự hình thành nano bạc với các điều kiện nhiệt độ, bao gồm: nhiệt độ phòng (khoảng $30^{\circ} \mathrm{C}$ ), $55^{\circ} \mathrm{C}$, $70^{\circ} \mathrm{C}, 80^{\circ} \mathrm{C}, 90^{\circ} \mathrm{C}$ và $100^{\circ} \mathrm{C}$. Phản ứng xảy ra trong 30 phút ở $\mathrm{pH}$ 8. Kết quả thí nghiệm cho thấy ở các nhiệt độ cao từ $80-100^{\circ} \mathrm{C}$, sự hình thành nano bạc là tốt hơn nhiều so với ở nhiệt độ thấp, và tối ưu tại nhiệt độ $80^{\circ} \mathrm{C}$.

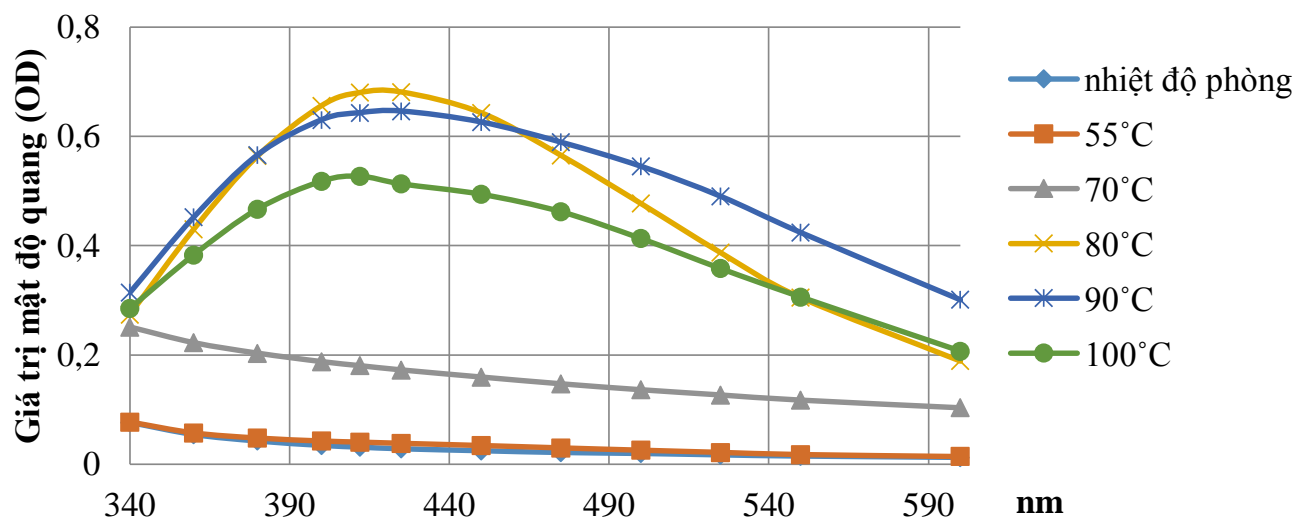

Hình 5. Ảnh hưởng của nhiệt độ lên khả năng tạo nano bạc từ dịch chiết củ gừng.

3.6. Ảnh hương của thời gian lên khả năng tạo nano bac

Trong quá trình phản ứng, hạt nano bạc dần được tạo thành. Do sự bất ổn định của hạt nano bạc nên chúng ta cần tìm một thời gian tối ưu, tại đó hạt nano bạc được tạo ra nhiều nhất và không bị kết tụ, vì thông thường sau khoảng thời gian tối ưu, các hạt nano bạc có xu hướng kết tụ lại với nhau và làm tăng kích thước của hạt. Kết quả nghiện cứu cho thấy phản ứng tạo hạt nano bạc xảy ra khá nhanh. Chỉ sau 15 phút là phản ứng gần như hoàn toàn và dạt cực đại sau 30 phút với gián trị $\mathrm{OD}_{\max }=0.716$, tại bước sóng $\lambda=412 \mathrm{~nm}$. Khối lượng củ gừng sử dụng: $5 \mathrm{~g}$

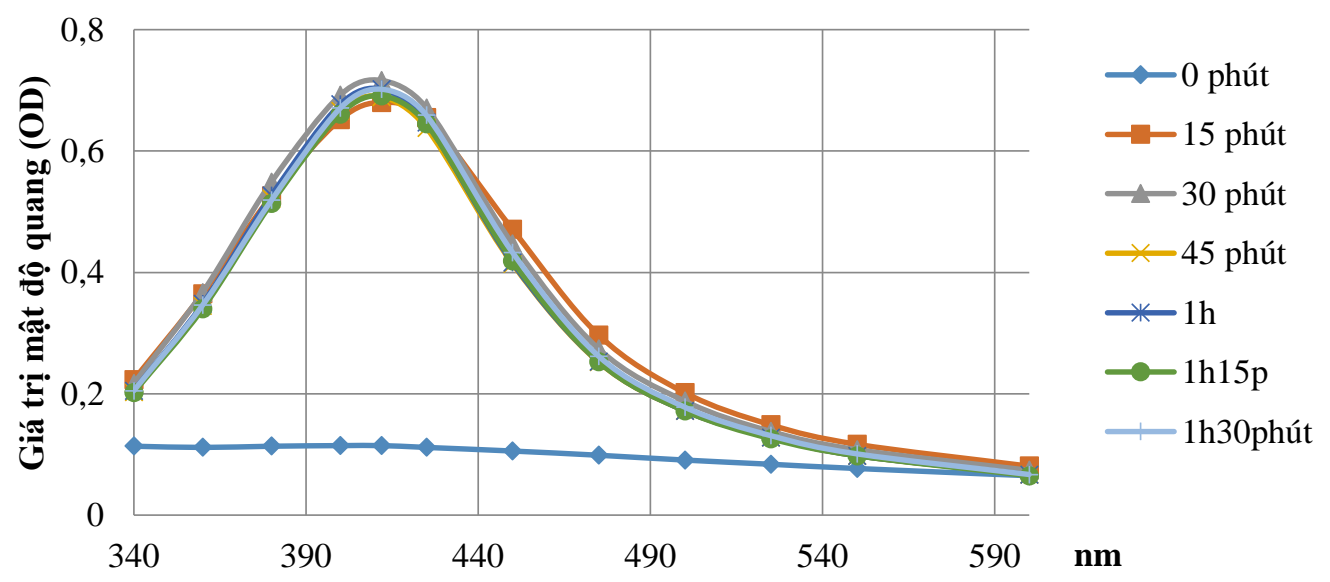

Hình 6. Ảnh hưởng của thời gian lên khả năng tạo nano bạc. 


\section{7. Đánh giá khả năng kháng khuẩn của dung dịch nano bac}

Dung dịch nano bạc được tạo ra trong điều kiện tối ưu, bao gồm: nng độ $\mathrm{AgNO}_{3}: 3 \mathrm{mM}$; tỷ lệ dịch chiết/dung dịch $\mathrm{AgNO}_{3}$ : 1/5, nhiệt độ: 80 ${ }^{\circ} \mathrm{C}, \mathrm{pH}: 12$, thời gian phản ứng: 30 phút. Để đánh giá khả năng kháng khuẩn của hạt nano bạc tạo
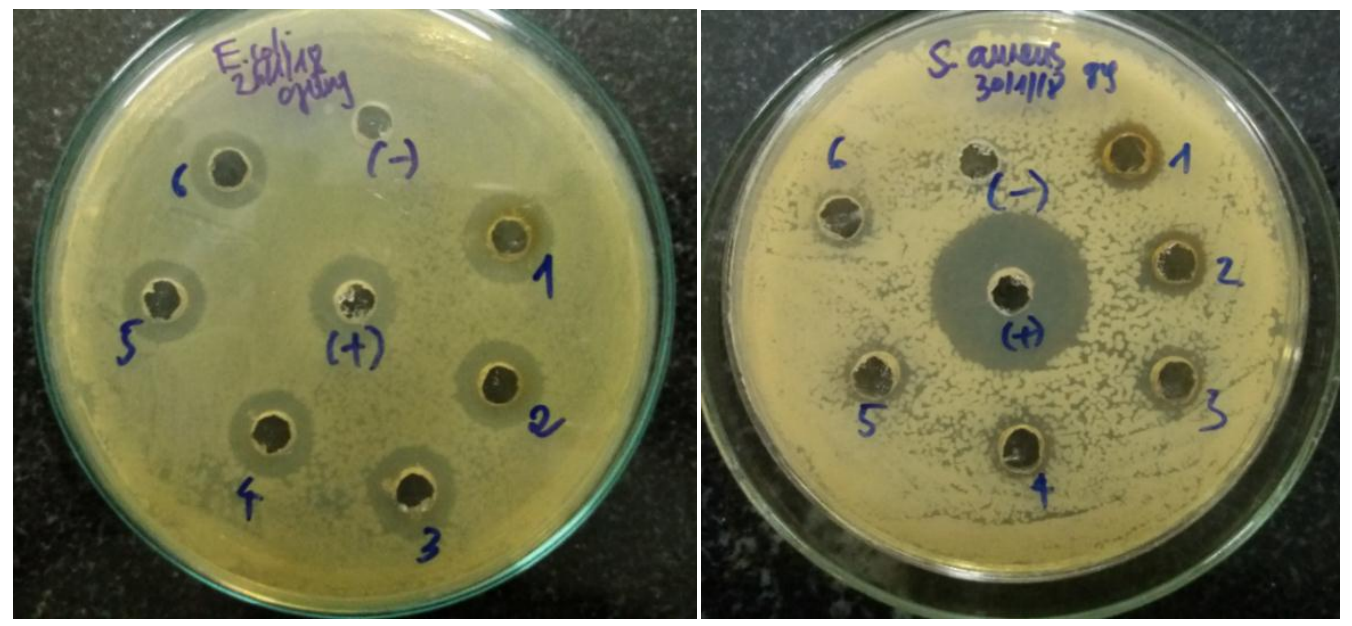

Hình 7. Hình ảnh vòng kháng khuẩn trên đĩa thạch do dung dịch nano bạc tạo từ dịch chiết củ gừng đến khả năng kháng $E$. coli và $S$. aureus.

Bảng 1. Khả năng kháng khuẩn của dung dịch nano bạc tạo từ dịch chiết củ gừng

\begin{tabular}{lll}
\hline & \multicolumn{2}{l}{$\begin{array}{l}\text { Đường kính vòng vô khuẩn } \\
(\mathrm{mm})\end{array}$} \\
\cline { 2 - 3 } & E. coli & S. aureus \\
\hline $\begin{array}{l}\text { Đối chứng dương } \\
\text { (kháng sinh) }\end{array}$ & 9 & 17 \\
Đối chứng âm & 0 & 0 \\
Không pha loãng & 9 & 6 \\
Pha loãng 2 lần & 8.5 & 5 \\
Pha loãng 3 lần & 7 & 4.5 \\
Pha loãng 4 lần & 7 & 4.5 \\
Pha loãng 5 lần & 6 & 4 \\
Pha loãng 10 lần & 5.5 & 3.5 \\
\hline
\end{tabular}

Kết quả phân tích bằng phương pháp khuếch tán trên giếng thạch cho thấy, hạt nano bạc tạo từ dịch chiết củ gừng đều có tác dụng ức chế hai chủng vi sinh vật thử nghiệm. Nồng độ nano bạc càng cao, khả năng kháng khuẩn càng tốt. Hạt nano bạc thể hiện hoạt tính kháng khuẩn tốt hơn từ dịch chiết củ gừng, tiến hành thử nghiệm trên cả hai chủng vi khuẩn là $E$. coli và $S$. aureus. Đầy là hai chủng vi khuẩn gây bệnh trên người và đại diện cho vi khuẩn Gram (-) và vi khuẩn Gram (+). Kết quả khuếch tán trên đĩa thạch (hình 7) và được trình bày cụ thể ở bảng 1 . 
Chúng tôi cũng đã tối ưu được các thông số hóa lý ảnh hưởng đến quá trình hình thành hạt nano bạc, một cách cụ thể như sau: nồng độ dung dịch ion bạc $\left(\mathrm{AgNO}_{3}\right): 3 \mathrm{mM}$; tỉ lệ dịch chiết/dung dịch $\mathrm{AgNO}_{3}$ : 1/5; nhiệt độ: $80{ }^{\circ} \mathrm{C}$; $\mathrm{pH}$ : 10 ; thời gian phản ứng: 30 phút. Các kết quả nghiên cứu tính khánh khuẩn cũng đã chứng minh rằng các dung dịch nano bạc tạo từ dịch chiết củ gừng đều thể hiện khả năng kháng khuẩn với cả hai chủng vi khuẩn $E$. coli và $S$. aureus, tuy nhiên khả năng kháng khuẩn trên chủng vi khuẩn Gram (-) tốt hơn trên chủng Gram (+). Từ các kết quả thu được, chúng tôi kết luận rằng sử dụng dịch chiết củ gừng để tạo dung dịch nano bạc có thể thực hiện được một cách dễ dàng, hiệu quả tốt trong các điều kiện không khắt khe. Dung dịch nano bạc có thể ứng dụng trong việc kháng lại các vi sinh vật gây bệnh trong môi trường.

\section{Lời cảm ơn}

Nghiên cứu này được thực hiện dưới sự tài trợ kinh phí từ đề tài nghiên cứu mang mã số KLEPT-18-01, do TS. Nguyễn Đình Thắng làm chủ nhiệm đề tài.

\section{Tài liệu tham khảo}

[1] L.S. Li, J. Hu, W. Yang, P. Alivisatos. Band gap variation of size- and shape-controlled colloidal CdSe quantum rods. Nano Lett. 1 (2001) 49-51. https://doi.org/10.1021/nl015559r.

[2] A.P. Nikalje. Nanotechnology and its Applications in Medicine. Medicinal chemistry 5(2015) 81-89.

[3] G. Doria, J. Conde, B. Veigas et al. Noble metal nanoparticles for biosensing applications. Sensors 12 (2012) 1657-1687. https://doi.org/ 10.4172/2161 $-0444.1000247$.

[4] A.J. Haes, A.D. McFarlan, R.P. van Duyne. Nanoparticle optics: sensing with nanoparticle arrays and single nanoparticles. The International Society for Optical Engineering 5223 (2003) 197207. https://doi.org/10.1039/C7NR03311G.

[5] A. Elham, M. Morteza, F.V. Sedigheh, K. Mohammad, A. Abolfazl, T. N. Hamid, N. Parisa, W.J. San, H. Younes, N-K. Kazem, S. Mohammad. Silver nanoparticcles: Synthesis methods, bio-applications and properties. Critical reviews in Microbiology 42 (2016) 173-180. https://doi.org/10.3109/1040841X.2014.912200.

[6] J. K. Pradeep, K. Chaudhury, V. S. Suresh, K. G. Sujoy. An emerging interface between life science and nanotechnology: present status and prospects of reproductive healthcare aided by nanobiotechnology. Nano Rev. 5 (2014): 10.3402/ nano. v5. 22762. https://doi.org/10.3402/nano.v5.22762.

[7] M. Danilcauk, A. Lund, J. Saldo, H. Yamada, J. Michalik. Conduction electron spin resonance of small silver particles. Spectrochimaca. Acta. Part A 63 (2006) 189-191. https://doi.org/10.1016/j.saa. 2005.05.002.

[8] J.L. Elechiguerra, J.L. Burt, J.R. Morones et al. Interaction of silver nanoparticles with HIV-1. Journal of Nanobiotechnology 3 (2005) 6. https:// doi.org/10.1186/1477-3155-3-6

[9] J.S. Kim, E. Kuk, K. Yu, J.H. Kim, S.J. Park, H.J. Lee, S.H. Kim, Y.K. Park, Y.H. Park, C.Y. Hwang, Y.K. Kim, Y.S. Lee, D.H. Jeong, M.H. Cho. Antimicrobial effects of silver nanoparticles. Nanomedicine 3 (2007) 95-101. https://doi.org/ 10.1016/j.nano.2006.12.001.

[10] Y. Matsumura, K. Yoshikata, S. Kunisaki, T. Tsuchido. Mode of bacterial action of silver zeolite and its comparison with that of silver nitrate. Appl. Environ. Microbiol. 69(2003) 42784281.https://doi.org/10.1128/AEM.69.7.4278-4281. 2003.

[11] M. Yamanaka, K. Hara, J. Kudo. Bactericidal Actions of a Silver Ion Solution on Escherichia coli, Studied by Energy-Filtering Transmission Electron Microscopy and Proteomic Analysis. Appl. Environ. Microbiol. 71 (2005) 7589-7593. https://doi.org/10.1128/AEM.71.11.7589-7593. 2005.

[12] Y.H. Hsueh, K.S. Lin, W.J. Ke, C.T. Hsieh, C.L. Chiang, D.Y. Tzou, S.T. Liu. The Antimicrobial Properties of Silver Nanoparticles in Bacillus subtilis Are Mediated by Released Ag+ Ions. PLoS One 10 (2015): e0144306. https://doi.org/ 10.1371/journal.pone.0144306.

[13] N. Kumar, S. Das, A. Jyoti, S. Kaushik. Synergistic effect of silver nanoparticles with doxycycline against Klebsiella pneumoniae. Int. J. Pharm. Sci. 8 (2016) 183-186.

[14] V.G. Borodina, Y.A. Mirgorod. Kinetics and Mechanism of Interaction between HAuCl4 and 
Rutin. Kinet. Cat. 55 (2014) 683-687. https://doi. org/10.1134/S0023158414060044.

[15] V.V. Makarov, A.J. Love, O.V. Sinitsyna, S.S. Makarova, I.V. Yaminsky, M.E. Taliansky, N.O. Kalinina. Green nanotechnologies: synthesis of metal nanoparticles using plants. Acta Naturae 6 (2014) 35-44. https://doi.org/10.1039/C1GC15 386B.

[16] M.S. Butt, M.T. Sultan. Ginger and its health claims: molecular aspects. Critical Reviews in
Food Science and Nutrition 51 (2011) 383-393. https://doi.org/10.1080/10408391003624848.

[17] M. Park, J. Bae, D.S. Lee. Antibacterial activity of gingerol and gingerol isolated from ginger rhizome against periodontal bacterial. Phytotherapy Research 22 (2008) 1446-1449. https://doi.org/10.1002/ptr.2473.

[18] Y. Shukla, M. Singh. Cancer preventive properties of ginger: a brief review. Food and Chemical Toxicology 45 (2007) 683-690. https://doi.org/10. 1016/j.fct.2006.11.002. 